\title{
Shock and spall behaviors of a high specific strength steel: Effects of impact stress and microstructure
}

Wei Wang, Husheng Zhang, Muxin Yang, Ping Jiang, Fuping Yuan, and Xiaolei Wu

Citation: Journal of Applied Physics 121, 135901 (2017); doi: 10.1063/1.4979346

View online: http://dx.doi.org/10.1063/1.4979346

View Table of Contents: http://aip.scitation.org/toc/jap/121/13

Published by the American Institute of Physics

\section{Articles you may be interested in}

Controlling shockwave dynamics using architecture in periodic porous materials

Journal of Applied Physics 121, 135102 (2017); 10.1063/1.4978910

Time resolved small angle X-ray scattering experiments performed on detonating explosives at the advanced photon source: Calculation of the time and distance between the detonation front and the x-ray beam Journal of Applied Physics 121, 105902 (2017); 10.1063/1.4978036

Equation of state of Mo from shock compression experiments on preheated samples Journal of Applied Physics 121, 115904 (2017); 10.1063/1.4978607

Optical absorbances of $\mathrm{Gd}_{3} \mathrm{Ga}_{5} \mathrm{O}_{12}$ single crystals under shock compression to $211 \mathrm{GPa}$ Journal of Applied Physics 121, 145901 (2017); 10.1063/1.4979634

Spall fracture and twinning in laser shock-loaded single-crystal magnesium Journal of Applied Physics 121, 165104 (2017); 10.1063/1.4982352

An iterative forward analysis technique to determine the equation of state of dynamically compressed materials Journal of Applied Physics 121, 195901 (2017); 10.1063/1.4983067

\section{AIP $\mid$ Journal of}

Save your money for your research.

It's now FREE to publish with us no page, color or publication charges apply.
Publish your research in the Journal of Applied Physics

to claim your place in applied

physics history. 


\title{
Shock and spall behaviors of a high specific strength steel: Effects of impact stress and microstructure
}

\author{
Wei Wang, ${ }^{1,2}$ Husheng Zhang, ${ }^{1}$ Muxin Yang, ${ }^{1}$ Ping Jiang, ${ }^{1}$ Fuping Yuan, ${ }^{1,2, a)}$ \\ and Xiaolei $\mathrm{Wu}^{1,2}$ \\ ${ }^{1}$ State Key Laboratory of Nonlinear Mechanics, Institute of Mechanics, Chinese Academy of Sciences, \\ No. 15, North 4th Ring, West Road, Beijing 100190, China \\ ${ }^{2}$ School of Engineering Science, University of Chinese Academy of Sciences, Beijing 100190, China
}

(Received 22 December 2016; accepted 16 March 2017; published online 3 April 2017)

\begin{abstract}
A series of plate-impact experiments were conducted to investigate the influences of impact stress and microstructure on the shock and spall behaviors of a high specific strength steel (HSSS). The HSSS shows a strong positive strain rate sensitivity on the yield strength. With increasing impact stress up to about $6 \mathrm{GPa}$, the spall strength is found to decrease significantly and then levels off with further increasing impact stress. This trend is proposed to be attributed to the accumulation damage within the target as the initial shock-induced compression wave propagates through the target. The microcracks are clearly observed to nucleate from the interfaces between $\gamma$-austenite and B2 phase and propagate along the interfaces or cut through the B2 phase in the HSSS during the spalling process. The Hugoniot elastic limit and the spall strength were found to be highly dependent on the microstructure. The spall strength was found to be higher when the density of the void nucleation sites is lower, indicating that the spall strength should be a microstructure parameter of the HSSS under impact tensile conditions depending on the density of phase interfaces. It was also found that there is a tradeoff between the specific yield strength and the spall strength for this HSSS; thus, the current findings should provide insights for achieving an optimal combination of both mechanical properties for impact-resistant applications by tailoring the microstructure. Published by AIP Publishing. [http://dx.doi.org/10.1063/1.4979346]
\end{abstract}

\section{INTRODUCTION}

High-strength and high-ductility steels are always desirable in various applications, such as automobiles, aerospace, aviation, and military defense. Such expectations have been realized in recent decades through several design principles, such as twinning-induced plasticity (TWIP) steels, ${ }^{1,2}$ transformation-induced plasticity (TRIP) steels, ${ }^{3}$ dual-phase (DP) steels, ${ }^{4}$ and nano-structured steels. ${ }^{5}$ Moreover, lowdensity steels, mainly based on the Fe-Al-Mn-C alloy system, have been developed and widely studied due to their increased specific strength. ${ }^{6-13}$ These low-density steels, the so-called "TRIPLEX" steels, are mainly composed of both the fcc austenite matrix and the bcc ferrite matrix and finely dispersed nanometer-sized $\kappa$-carbides with the $(\mathrm{Fe}, \mathrm{Mn})_{3}$ AlC type. ${ }^{11}$

More recently, a high specific strength steel (HSSS) with a new composition of Fe-16Mn-10Al-0.86C-5Ni has been developed ${ }^{13}$ in which the excellent combination of specific strength and elongation is achieved, when compared to other high-specific-strength alloys. This HSSS has a low density of $6.8 \mathrm{~g} / \mathrm{cm}^{3}{ }^{3}{ }^{13}$ The outstanding mechanical properties have been attributed to a soft fcc austenite with the case of precipitation strengthening by a brittle and nondeformable FeAl-type (B2) intermetallic compound. ${ }^{13}$ However, the plastic deformation in most high-strength steels should be considered as composite-like deformation,

\footnotetext{
a) Author to whom correspondence should be addressed. Electronic mail: fpyuan@lnm.imech.ac.cn. Tel.: +86 10 82544409. Fax: +86 1082543977.
}

and the stress and strain partitioning between the constituent phases should play an important role due to the pronounced plastic heterogeneity between the constituent phases, as well as among grains with different Schmidt factors. Complex internal back stresses should be induced by the plastic heterogeneity, enabling a high strain hardening and a large ductility. The back-stress-induced strain hardening has been reported to contribute to the large uniform elongation in TWIP steels, ${ }^{1,14}$ TRIP steels, ${ }^{15}$ and DP steels. ${ }^{16,17}$ In our previous research, ${ }^{18}$ we have also shown that the HSSS developed by Kim et al. ${ }^{13}$ is better understood as a dual-phase microstructure since the B2 phase is deformable. Moreover, the stress/strain partitioning and the back-stress-induced strain hardening have been proven to play an important role during the plastic deformation for this HSSS based on in situ high energy X-ray diffraction data, scanning electron microscopy (SEM) images of samples before and after tensile tests, and the back stress measurement from tensile load-unloadreload (LUR) tests.

Stronger and tougher metals and alloys along with the comprehensive understanding of deformation physics subjected to shock loading could provide insights into potential applications, such as improved armor systems and advanced impact-tolerant structures. ${ }^{19}$ The shock responses of materials have been investigated typically by plate impact experiments, ${ }^{20,21}$ in which the shock wave structure, the shock Hugoniot elastic limit (HEL), and the spall strength can be obtained. ${ }^{20}$ As we know, spallation is the tensile failure of materials under shock conditions due to the development of 
tensile stresses in the interior of samples by the overlap of two release waves. ${ }^{22}$ In the past several decades, using plate impact experiments, spall strengths have been studied and determined in various metals and alloys, such as aluminum and alloys, ${ }^{23-25}$ copper, $^{26}$ tantalum, ${ }^{27}$ magnesium alloy, ${ }^{28}$ and steels. ${ }^{29-34}$ These studies have also shown that the spall strengths of metals and alloys are highly dependent on the microstructures (i.e., grain size, dislocation density, twins, and texture), the temperature, the shock compression stress, and the tensile stress/strain rates.

The HSSS provides a perfect candidate for a major improvement in the impact resistance and the ballistic performance in a variety of impact-tolerant structures due to the excellent combination of specific strength and ductility. In this regard, in the present study, a series of plate impact experiments have been conducted to investigate the shock wave structure, the HEL, and the spall strength in the HSSS. The focus of this paper is to understand the effects of the microstructure and the shock compression stress on the HEL, the spall strength, and the related void nucleation mechanisms during spallation for the HSSS.

\section{MATERIALS, PROCEDURES OF MICROSTRUCTURAL CHARACTERIZATION, AND TENSILE TESTS}

Similar to the procedures in our previous research, ${ }^{18}$ an Fe-16.4Mn-9.9Al-0.86C-4.8Ni-0.008P-0.004S (wt.\%) HSSS was produced using arc melting in a high frequency induction furnace under a pure argon atmosphere and then cast into a cylindrical ingot with a diameter of $130 \mathrm{~mm}$ and a length of $200 \mathrm{~mm}$. The ingot was first homogenized at $1180^{\circ} \mathrm{C}$ for $2 \mathrm{~h}$ and then hot forged into slabs with a thickness of $14 \mathrm{~mm}$ in between $1150^{\circ} \mathrm{C}$ and $900^{\circ} \mathrm{C}$. With a starting temperature of $1100^{\circ} \mathrm{C}$, the hot forged slabs were hot-rolled into strips with a thickness $9.2 \mathrm{~mm}$. The hot-rolled strips were annealed at $1000^{\circ} \mathrm{C}$ for $1 \mathrm{~h}$ and then were cold rolled (CR) finally into sheets with the final thickness of $4.6 \mathrm{~mm}$. No cracks were found on the two surfaces of the CR sheets. The $\mathrm{CR}$ sheets were then annealed at $900{ }^{\circ} \mathrm{C}$ for $15 \mathrm{~min}$ (annealed state 1) or at $1000^{\circ} \mathrm{C}$ for $1 \mathrm{~h}$ (annealed state 2) immediately followed by quenching with water.

After materials' preparation, the microstructures of the HSSS were characterized by optical microscopy (OM), SEM, and transmission electron microscopy (TEM). The details of the sample preparations and the operation procedures for obtaining OM, SEM, and TEM images can be found in our previous paper. ${ }^{18}$ In the present study, two microstructures (annealed state 1 and annealed state 2) were considered in order to study the effects of the microstructure on the shock and spall behaviors. Before plate impact experiments, the quasi-static uniaxial tensile tests are also carried out to obtain the yield strength, the strain hardening behaviors, and the uniform elongation under quasi-static uniaxial stress conditions for two different microstructures, and these properties will then be used to qualitatively reveal the effects of the microstructure on the shock and spall behaviors. The dog-bone-shaped plate specimens, with a gage length of $18 \mathrm{~mm}$ and a width of $4 \mathrm{~mm}$, were used in the tensile tests.
For the annealed samples, the tensile loading axis was parallel to the initial rolling direction. The quasi-static uniaxial tensile tests were performed using an MTS Landmark testing machine under a strain rate of $5 \times 10^{-4} \mathrm{~s}^{-1}$ at room temperature, and the other procedures and the details about the tensile tests can also be found in our previous paper. ${ }^{18}$

\section{EXPERIMENTAL TECHNIQUES OF PLATE-IMPACT EXPERIMENTS AND WAVE PROPAGATION ANALYSIS}

The plate impact spall experiments have been conducted using the single-stage gas gun facility, and the schematic of the experimental configuration is shown in Fig. 1. A projectile carrying a HSSS flyer plate (with a diameter of $100 \mathrm{~mm}$ ) is accelerated along the gun barrel by high pressure nitrogen (for impact velocity lower than $300 \mathrm{~m} / \mathrm{s}$ ) or hydrogen (for impact velocity higher than $300 \mathrm{~m} / \mathrm{s}$ ) to impact the stationary HSSS target (with a diameter of $25 \mathrm{~mm}$ ). The plate impact is designed to take place in a chamber with a high vacuum environment ( $<10 \mathrm{~Pa}$ prior to impact) in order to reduce or avoid the possibility of air cushion between the flyer and the target plates. The flyer and target plates were carefully aligned to be parallel within $1 \times 10^{-3}$ radians prior to the impact in order to ensure the generation of plane waves, which is sufficiently parallel to the impact surface. The velocity of the projectile was measured using a pair of coaxial electric probes. The history of the normal particle velocity at the rear surface of the target plate was measured and recorded using a photonic Doppler velocimetry (PDV) system and a high-speed oscilloscope $(8 \mathrm{GHz})$. The high-speed oscilloscope was triggered once the isolated pins buried in the flyer and target holders were flushed with the impact surfaces and shorted to the ground. The flyer and target plates were also collected with soft recovery after impact for further microstructural observations. The other details regarding the design and the execution of the plate impact experiments can be found elsewhere. ${ }^{20}$

Based on the previous research, ${ }^{20,22,24}$ it is well known that compressive shock waves are first generated in both the flyer and the target plates upon impact, and then a state of tensile stress is generated at a predetermined location within the target plate through the interaction of the two release waves from the free surfaces of both the flyer and the target plates. A tensile spall process (usually with a small duration of time) can be initiated once the tensile stress exceeds a critical value for the materials (spall strength), and the

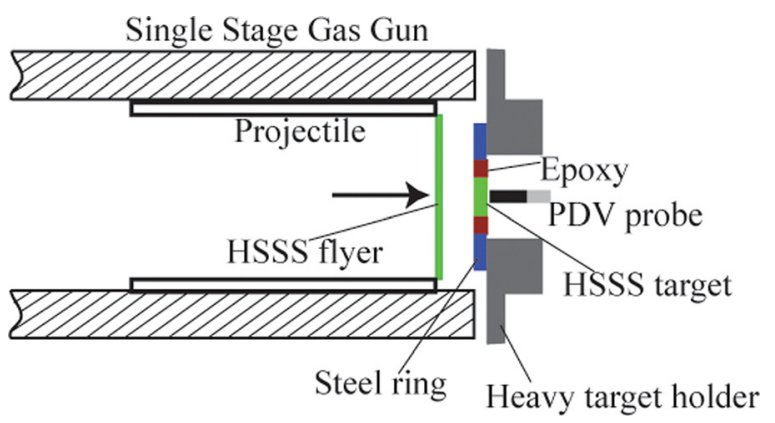

FIG. 1. Schematic illustration of the plate impact spall experiments for the HSSS. 


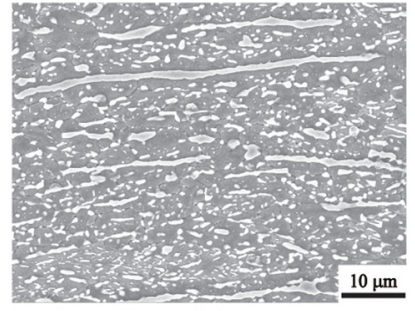

(a)

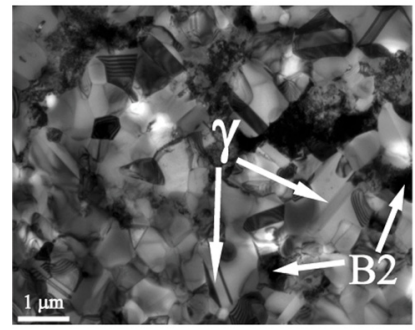

(c)

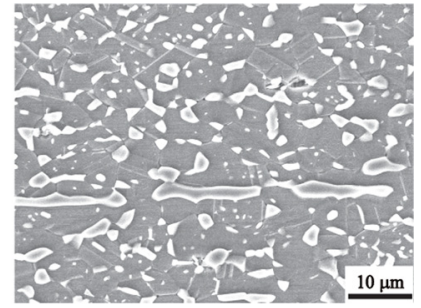

(b)

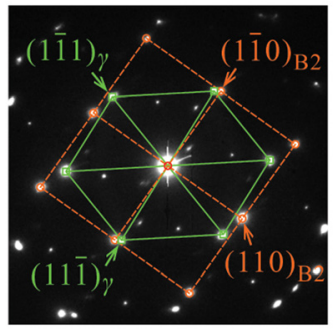

(d)
FIG. 2. ( $a$ and b) SEM images of cross sections for samples with annealed state 1 and annealed state 2 , respectively. (c) TEM image showing the microstructures of $\gamma$-austenite and B2 phase for annealed state 1. (d) The indexed selected area diffraction pattern for the TEM image with an electron beam closely parallel to both the $[011]_{\gamma}$ and $[001]_{\mathrm{B} 2}$ zone axes.

occurrence of spallation can be identified through the typical pull back signal from the free surface velocity profiles. The other details regarding the description for all stress and particle velocity states during a typical plate-impact spall experiment can be found elsewhere. ${ }^{20,22,24}$

\section{RESULTS AND DISCUSSION}

\section{A. Results of microstructural characterization and quasi-static tensile tests}

The microstructural characterizations of the two states (annealed state 1 and annealed state 2) are shown in Fig. 2. After cold rolling, two phases are visible, of which one is the fcc $\gamma$-austenite with an elongated shape and the other is the lamellar B2 (FeAl intermetallic compound) phase with a large aspect ratio, as indicated in our previous paper. ${ }^{18}$ After annealing at $900{ }^{\circ} \mathrm{C}$ for $15 \mathrm{~min}$, the $\gamma$-austenite is the equiaxed recrystallized grains, while both granular and lamellar B2 phase precipitates are observed, as shown in Fig. 2(a). When annealed at $1000^{\circ} \mathrm{C}$ for $1 \mathrm{~h}$, the sizes of both $\gamma$-austenite and B2 phase are much larger than those for annealed state 1, as shown in Fig. 2(b). Fig. 2(c) shows the TEM image of annealed state 1. Fig. 2(d) shows the corresponding indexed selected area diffraction pattern for the TEM image. It is observed that the $\mathrm{B} 2$ phase is much inclined to precipitate at either the grain boundaries or triple junctions of the $\gamma$-austenite matrix, instead of the $\gamma$ grain interiors. Both $\gamma$ and B2 grains are nearly free of dislocations for the annealed state at high temperature $\left(900^{\circ} \mathrm{C}\right)$, and annealing twins are often seen in the $\gamma$-austenite grains.

The quasi-static tensile tests have been conducted on the two microstructures of the HSSS to reveal their quasi-static tensile properties, which are shown in Fig. 3. Fig. 3(a) displays the engineering stress versus engineering strain curves, while Fig. 3(b) shows the true stress versus true strain curves. After being annealed at $900^{\circ} \mathrm{C}$ for $15 \mathrm{~min}$, the HSSS shows a good combination of yield strength $(\sim 1.22 \mathrm{GPa})$ and uniform elongation $(\sim 30 \%)$. Moreover, annealed state 1 has a very high strain hardening ability after yielding $\left(\Delta \sigma=\sigma_{U T S}\right.$ $-\sigma_{Y} \sim 0.57 \mathrm{GPa}$, which is deduced from the true stress-strain curve). When annealed at $1000{ }^{\circ} \mathrm{C}$ for $1 \mathrm{~h}$, the yield strength is lower $(\sim 0.73 \mathrm{GPa})$, while the uniform elongation is as high as $\sim 35 \%$. It should be noted that both microstructures have high specific yield strengths (180 and $108 \mathrm{MPa} \mathrm{g}^{-1} \cdot \mathrm{cm}^{3}$ for annealed state 1 and annealed state 2, respectively), given a lower density for this $\operatorname{HSSS}\left(6.8 \mathrm{~g} / \mathrm{cm}^{3}\right)$ as compared to $7.8 \mathrm{~g} / \mathrm{cm}^{3}$ for conventional steels. Most importantly, the strain hardening ability for annealed state 2 increases to a much higher value $(\Delta \sigma \sim 0.77 \mathrm{GPa})$ when compared to that of the samples with annealed state 1 .

\section{B. Shock and spall behaviors of the HSSS}

In the present paper, a series of experiments were conducted in annealed state 1 at various impact velocities (116.5 to $547.9 \mathrm{~m} / \mathrm{s}$ ) to understand the structure of shock waves better, obtain the HEL, and estimate the spall strength as a function of increasing levels of shock compression stress. Additional experiments were also performed on the samples with annealed state 2 at an impact velocity of approximately $550 \mathrm{~m} / \mathrm{s}$ to study the microstructure effect on the shock and spall behaviors of the HSSS. The key parameters for all experiments are summarized in Table I, including the shot \#,

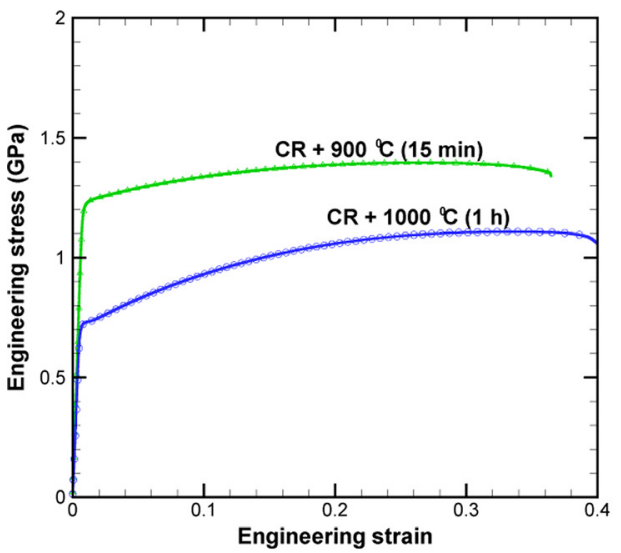

(a)

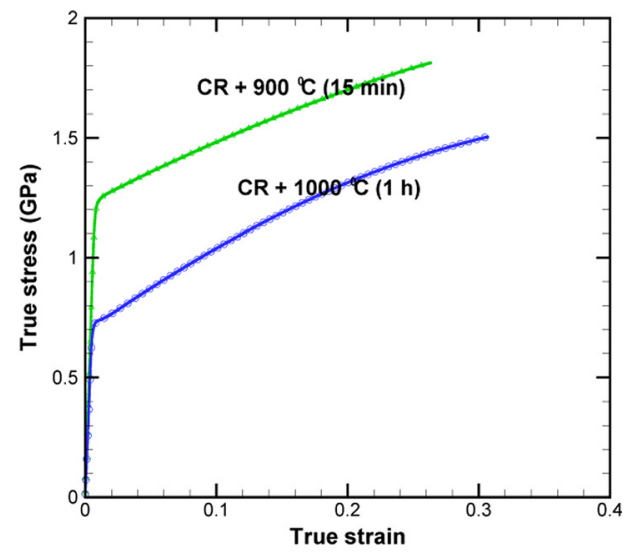

(b)
FIG. 3. (a) Tensile engineering stressstrain curves for various microstructures at a strain rate of $5 \times 10^{-4} \mathrm{~s}^{-1}$. (b) Tensile true stress-strain curves for various microstructures at a strain rate of $5 \times 10^{-4} \mathrm{~s}^{-1}$ 
TABLE I. The key parameters for all plate impact spall experiments.

\begin{tabular}{llccc}
\hline \hline Shot \# & Microstructure & $\begin{array}{c}\text { Flyer } \\
\text { thickness } \\
(\mathrm{mm})\end{array}$ & $\begin{array}{c}\text { Target } \\
\text { thickness } \\
(\mathrm{mm})\end{array}$ & $\begin{array}{c}\text { Impact } \\
\text { velocity } \\
(\mathrm{m} / \mathrm{s})\end{array}$ \\
\hline 01A1 & Annealed state 1 & 2.16 & 4.60 & 116.5 \\
02A1 & Annealed state 1 & 2.13 & 4.54 & 174.9 \\
03A1 & Annealed state 1 & 2.12 & 4.58 & 240.2 \\
04A1 & Annealed state 1 & 2.16 & 4.54 & 333.3 \\
05A1 & Annealed state 1 & 2.14 & 4.49 & 547.9 \\
01A2 & Annealed state 2 & 2.12 & 4.39 & 560.3 \\
\hline \hline
\end{tabular}

the microstructure, the thickness of the flyer, the thickness of the target, and the impact velocity. The lateral dimensions of the flyer and the target plates were designed sufficiently large to avoid the arrival of the release waves from the lateral boundary at the monitoring point of PDV during the time duration of interest.

\section{Effect of shock compression stress on the shock and spall behaviors of the HSSS}

In these experiments for annealed state 1, the impact velocity is varied from 116.5 to $547.9 \mathrm{~m} / \mathrm{s}$, spanning from the elastic to the elastic-plastic range for the samples of annealed state 1 during impact. The measured free surface velocity history profiles for experiments on annealed state 1 are shown in Fig. 4(a). When the impact velocity is as low as $116.5 \mathrm{~m} / \mathrm{s}$, the elastic precursor jumps to a level of $\sim 110 \mathrm{~m} / \mathrm{s}$ and then remains nearly constant up to the arrival of the spall wave at the free surface of the target plate. This type of shock wave structure indicates a complete elastic response, and the stress level at the HEL for annealed state 1 should be higher than the impact stress of $2.46 \mathrm{GPa}$. At higher impact velocities, a clear two-wave structure is observed in the measured free-surface particle-velocity history profiles, indicating an elastic-plastic shock response: a step-like elastic precursor to the HEL level, followed by a slower plastic wave. These two-wave structures also suggest that no phase transformation occurs when the impact stress is below $10.00 \mathrm{GPa}$ (shock transformation pressure of iron is approximately $13 \mathrm{GPa}^{35}$ ) because the plastic wave and the phase transformation wave should separate, and the three-wave structures and multiple plateaus should be observed if there exists a phase transformation in the target materials.

The Hugoniot state for each experiment can be obtained from the Rankine-Hugoniot conservation relationships by using the peak free surface velocity $\left(V_{f s}^{p}\right)$, the shock velocities $\left(U_{s}\right.$ for elastic wave and $U_{p}$ for the plastic wave), and the density at zero pressure $\left(\rho_{0}\right){ }^{22}$ Since the two-wave structures are observed in the present study, the stress at the HEL point can be calculated using the jump conditions for the elastic wave, while the stress exceeding HEL can be calculated using the jump conditions for the plastic wave.

Thus, the stress and the strain at the HEL point can be calculated as follows by using the free surface velocity at the HEL point $\left(V_{f s}^{H E L}\right)$ :

$$
\begin{gathered}
\sigma_{H E L}=\frac{1}{2} \rho_{0} U_{s} V_{f s}^{H E L}, \\
\varepsilon_{H E L}=\frac{1}{2} \frac{V_{f s}^{H E L}}{U_{s}} .
\end{gathered}
$$

The final Hugoniot stress and the final Hugoniot strain immediately behind the shock wave front can be calculated as follows:

$$
\begin{gathered}
\sigma_{H}=\sigma_{H E L}+\frac{1}{2} \rho_{0} U_{p}\left(V_{f s}^{p}-V_{f s}^{H E L}\right), \\
\varepsilon_{H}=\varepsilon_{H E L}+\frac{1}{2} \frac{\left(V_{f s}^{p}-V_{f s}^{H E L}\right)}{U_{p}} .
\end{gathered}
$$

The shock velocities $\left(U_{s}\right.$ and $U_{p}$ ) for each experiment can be estimated by the target thickness and the arrival times of the elastic wave and the plastic wave. The Hugonoit stress and the Hugonoit strain states obtained using the data from the five experiments for annealed state 1 and Eqs. (3) and (4) are shown in Fig. 4(b). A concave up shape of the Hugoniot curve is observed for the HSSS with annealed state 1. Based on Eqs. (1) and (2), the stress at the HEL for annealed state 1 can be estimated to be in the range of 2.88-3.39 GPa based on the free surface velocity profiles in Fig. 4(a). Besides exhibiting exceptional combination of specific strength and uniform elongation under quasi-static

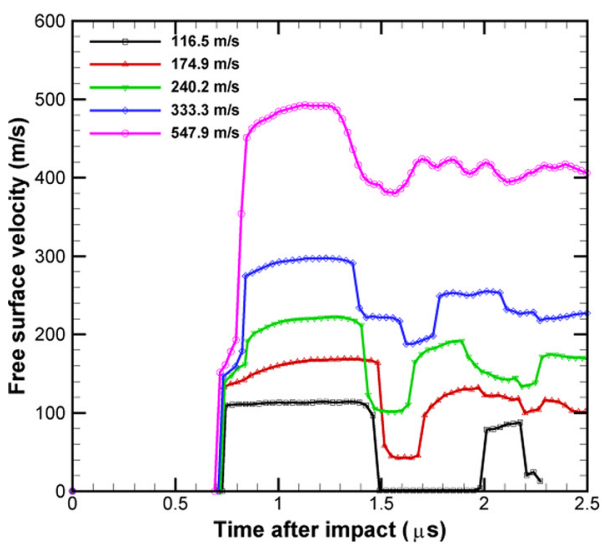

(a)

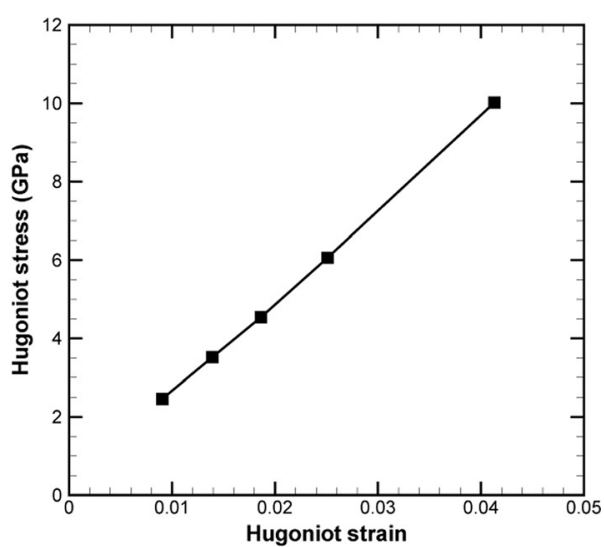

(b)
FIG. 4. (a) Free surface velocity history profiles for the five plate-impact spall experiments conducted at various impact velocities in the samples with annealed state 1. (b) Hugoniot stress vs. Hugoniot strain curve for the HSSS with annealed state 1 . 
uniaxial tensile conditions (as shown in Fig. 3), the HSSS for annealed state 1 also shows a relatively high average HEL $(\sim 3 \mathrm{GPa})$, when comparing with the other conventional crystalline alloys, ${ }^{29,36,37}$ such as austenitic stainless steel $(\sim 1.40 \mathrm{GPa})$, HY80 naval armor steel $(\sim 1.70 \mathrm{GPa})$, the fcc-structured manganese-containing high-entropy-alloy (HEA, $\sim 2.58 \mathrm{GPa})$, and the mild steel $(\sim 1.75 \mathrm{GPa})$. As indicated in Fig. 4(a), the width of the shock front is on the order of several hundreds of $\mu \mathrm{m}$; thus, the B2 phase with micron or even submicron size and the phase interfaces with high density in the shock front can be considered as effective barriers of slip dislocations, which provide significant strengthening in the yield stress under planar shock condition. The strain partitioning and the back-stressinduced strengthening in such inhomogeneous microstructures as the HSSS should also produce a strengthening effect in the shock front. ${ }^{18}$ These multiple strengthening mechanisms should contribute jointly to the observed much higher shock yield stress of the HSSS.

Moreover, the nominal strain rates for the initial elastic compression waves can be estimated using the strain at the HEL point divided by the rise time of the elastic wave:

$$
\dot{\varepsilon}_{\text {compression }}=\varepsilon_{H E L} / \Delta t \text {. }
$$

Then, the nominal strain rates for the yield strength under shock plane strain conditions (HEL) can be estimated to be about $4.8 \times 10^{5} \mathrm{~s}^{-1}$. Based on the von Mises yield criterion, the yield strength under plane strain shock loading, $\sigma_{H E L}$, can be related to the yield strength under uniaxial stress loading, $\sigma_{Y}{ }^{38}$

$$
\sigma_{H E L}=\sigma_{Y}\left(\frac{1-\nu}{1-2 v}\right)
$$

where $\sigma_{Y}$ and $\nu$ are the yield strength under uniaxial stress conditions and Poisson's ratio, respectively.

Based on Eq. (6) and using the ambient value of $\nu=0.3$ for most metals, the yield strengths under uniaxial stress conditions and at a high strain rate $\left(\sim 4.8 \times 10^{5} \mathrm{~s}^{-1}\right)$ were obtained to be in the range of $1.64-1.93 \mathrm{GPa}$, which is much higher than that $(1.22 \mathrm{GPa})$ under quasi-static conditions shown in Fig. 3. This indicates a positive strain rate sensitivity for annealed state 1 . The nominal strain rate for the shock compression wave is as high as $4.8 \times 10^{5} \mathrm{~s}^{-1}$ in the present plate impact experiments, and the moving velocity of mobile dislocations can possibly approach the shear wave velocity under such a shock loading condition. Thus, higher onset shear stress should be required for dislocation movement since the relativistic effects under such a shock condition could cause a substantial increment in the matter of viscosity. ${ }^{37}$ This could be one of the reasons as to why the HSSS shows a much higher dynamic yield strength under shock compression.

The spall strength can be obtained from the tensile stress amplitude, which can be calculated from the measured free surface velocities of $V_{\max }$ and $V_{\min }$ when the impact compression stress is below HEL ${ }^{39-43}$

$$
\sigma_{\text {spall }}=\frac{1}{2} \rho_{0} C_{0}\left(V_{\max }-V_{\min }\right) .
$$

However, when the impact stress is above HEL, the spall strength should be estimated with the following equation by considering the elastic-plastic response and the influence of the thickness of the spall layers: ${ }^{29}$

$$
\begin{aligned}
\sigma_{\text {spall }}= & \frac{1}{2} \rho_{0} C_{0}\left(V_{\max }-V_{\min }\right) \frac{1}{1+C_{0} / C_{b}} \\
& +\frac{h_{s p}}{2} \frac{d \sigma}{d t}\left(\frac{1}{C_{b}}-\frac{1}{C_{0}}\right),
\end{aligned}
$$

where $C_{b}$ is the bulk sound velocity, $h_{s p}$ is the thickness of the spall layer and can be obtained by the wave propagation analysis and the thicknesses of both the flyer and the target, and $d \sigma / d t$ is the tensile stress rate.

When the impact stress is below HEL, the spall strength calculation is straightforward and can be obtained by Eq. (7). As indicated in Eq. (8), the estimation of the spall strength is a little complicated when the impact stress is above HEL, and the determination of the tensile stress rate is illustrated in Fig. 5. The free surface velocity data for the experiment with an impact velocity of $547.9 \mathrm{~m} / \mathrm{s}$ are used as an example here. The elastic precursor wave and the plastic wave reach the free surface of the target at times $t_{1}$ and $t_{2}$, respectively. The release wave from the flyer plate reaches the target rear surface at time $t_{3}$, which leads to a drop in the measured free surface velocity. A new free surface is generated roughly in the middle of the target when the sample spalls; thus, the subsequent portion of the rarefaction wave as a compressive wave reaches the target rear surface at time $t_{4}$, resulting in a pullback signal. The spall fracture process produces a tensile loading duration between $t_{3}$ and $t_{4}$, and the time difference $\left(\Delta t=t_{4}-t_{3}\right)$ can be used to estimate the tensile stress rate and the tensile strain rate

$$
\begin{gathered}
\frac{d \sigma}{d t}=\frac{1}{2} \rho_{0} C_{0}\left(V_{\max }-V_{\min }\right) / \Delta t, \\
\frac{d \varepsilon}{d t}=\frac{\left(V_{\max }-V_{\min }\right)}{\Delta t} \times \frac{1}{2 C_{0}} .
\end{gathered}
$$

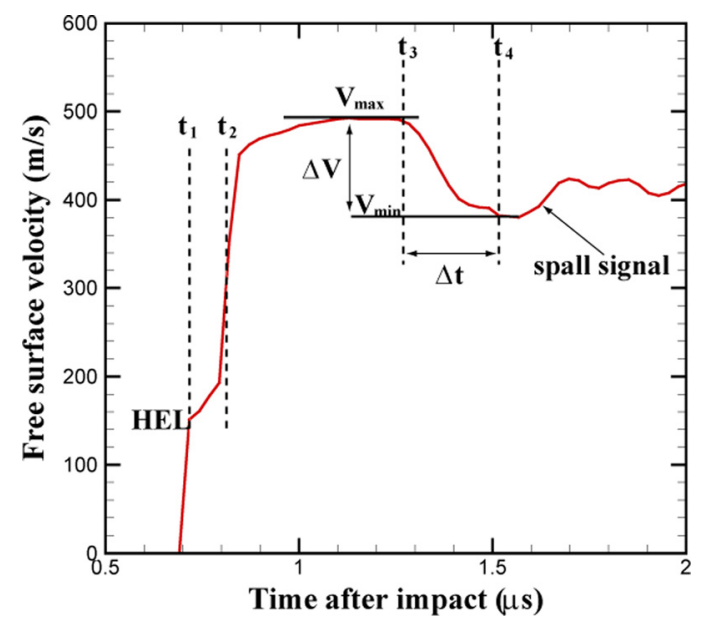

FIG. 5. The typical measured free surface velocity history profile to illustrate the calculation of spall strength when the impact stress is above HEL. 


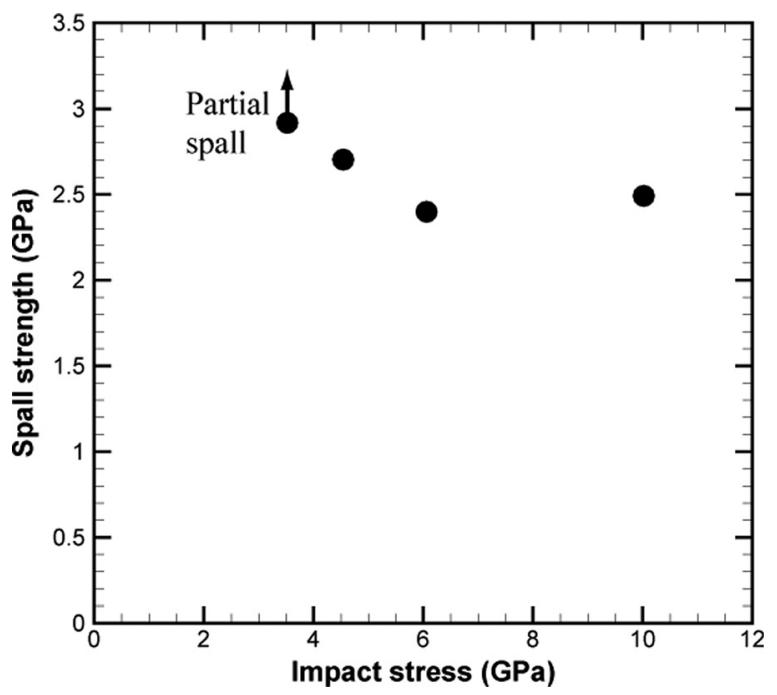

FIG. 6. Spall strength as a function of impact stress for the samples with annealed state 1 .

It should be ensured that both the thickness of the flyer and the target are kept fixed when discussing the effect of impact stress on the spall strength. The spall strength as a function of impact stress for annealed state 1 is plotted in Fig. 6. The impact stress varies in the range of $2.46-10.02 \mathrm{GPa}$, spanning from the elastic to elastic-plastic shock compression for annealed state 1 . It should be noted that no complete spallation occurs when the impact stress is lower than $3.52 \mathrm{GPa}$. Incipient spallation with discontinuous microcracks is observed for the case with an impact stress of $2.46 \mathrm{GPa}$, while partial spallation is observed for the case with an impact stress of $3.52 \mathrm{GPa}$. Thus, the spall strength for the case with an impact stress of $3.52 \mathrm{GPa}$ is lower bound, as pointed out by an upward arrow in Fig. 6. The spall strength is observed to decrease with increasing impact stress for annealed state 1 when the impact stress is lower than $6 \mathrm{GPa}$ and then levels off with further increasing impact stress. This trend is proposed to be attributed to the accumulation damage within the HSSS as the initial shock-induced compression wave propagates through the HSSS. The larger impact stress could induce larger amplitude of damage. It should be mentioned that similar variations in spall strength with increasing impact stress have also been reported in $\mathrm{BMG},{ }^{20} \mathrm{~S} 2$-glass fiber reinforced polymer composites, ${ }^{19}$ and AISI1020 mild steel. ${ }^{29}$

The scanning electron microscopy (SEM) images on the spall fracture surfaces for the recovered post-impact target pieces with annealed state 1 were also obtained for the experiments with different impact stresses, which are shown in Fig. 7. For annealed state 1, the spall fracture surfaces consist of ductile dimples for most areas. These dimples appear to be formed by pulling out the B2 particle during the dynamic tensile process. It is interesting to note that the size of the dimples decreases with increasing impact stress when the impact stress is lower than $6 \mathrm{GPa}$. The average dimple size is shown to be smaller for an impact stress of $6.06 \mathrm{GPa}$ (as calculated to be $1.89 \mu \mathrm{m}$ ) when compared to that for an impact stress of $4.54 \mathrm{GPa}$ (as calculated to be $2.25 \mu \mathrm{m}$ ). It might be possible that the B2 particles and the interfaces are damaged during the initial compression shock wave, and then the spall fracture is easier to occur due to these damages, resulting in smaller dimples at higher impact velocities, as shown in Fig. 7. The soft-recovery experiments and the detailed microstructure observations need be conducted in future to provide evidence for this suggested mechanism governing the shockweakening spall strength.

\section{$240.2 \mathrm{~m} / \mathrm{s}$}

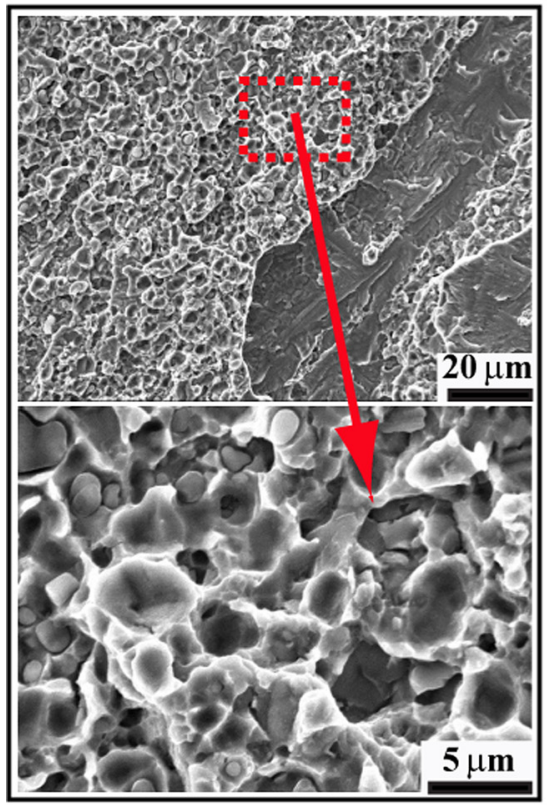

(a)
$333.3 \mathrm{~m} / \mathrm{s}$

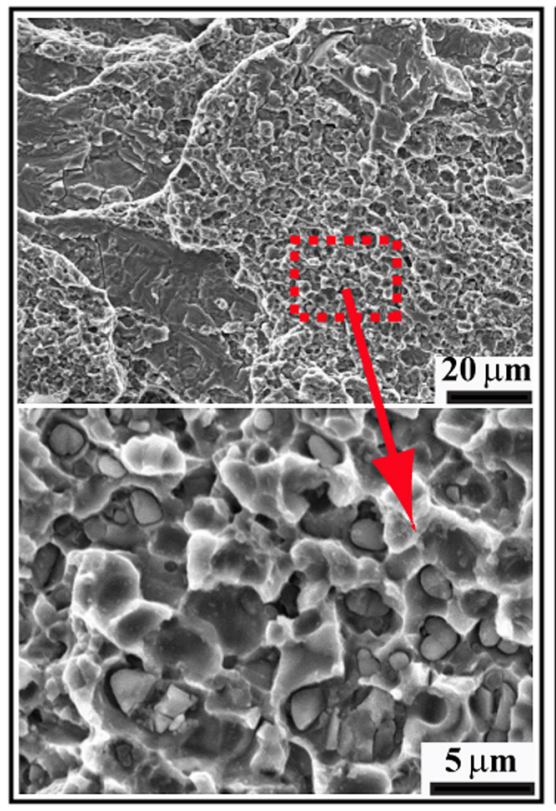

(b)
$560.3 \mathrm{~m} / \mathrm{s}$

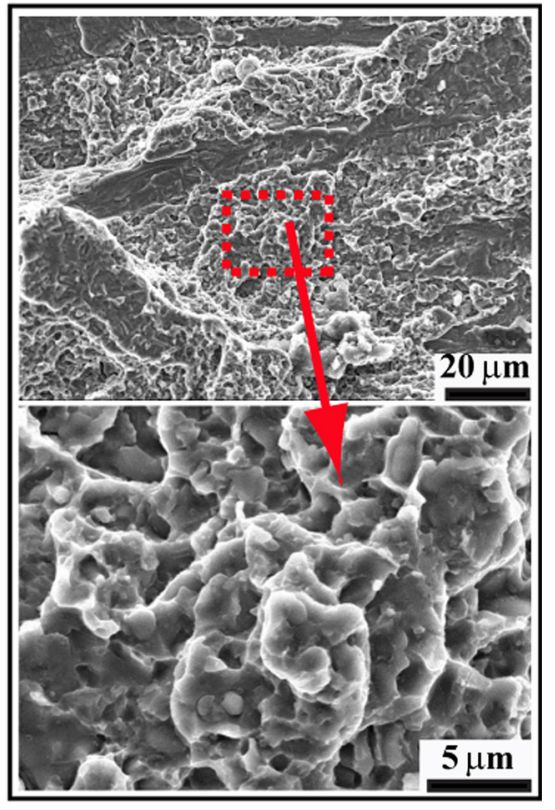

(c)

FIG. 7. SEM images of spall fracture surfaces for the samples with annealed state 1 at various impact velocities: (a) $240.2 \mathrm{~m} / \mathrm{s}$, (b) $333.3 \mathrm{~m} / \mathrm{s}$, and (c) $560.3 \mathrm{~m} / \mathrm{s}$. 
(a)

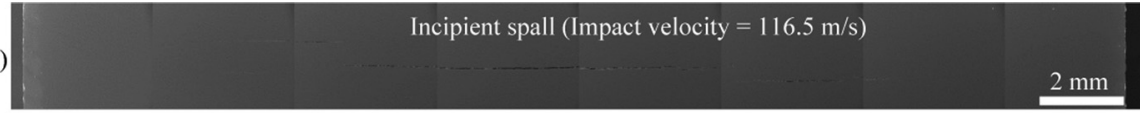

(b)

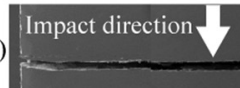

FIG. 8. SEM images of cross-sectional surfaces parallel to the impact direction for incomplete spall experiments: (a) incipient spall with an impact velocity of $116.5 \mathrm{~m} / \mathrm{s}$ and (b) partial spall with an impact velocity of $174.9 \mathrm{~m} / \mathrm{s}$.
Since no complete spallation occurs when the impact stress is lower than $3.52 \mathrm{GPa}$, the SEM micrographs of the cross-section along the impact axis could be used to investigate the nucleation and propagation mechanisms of microcracks for the HSSS (as shown in Figs. 8 and 9). As indicated in Fig. 8, a chain of microcracks are observed to form in the loading direction and then merge into a spall macrocrack propagating in the transverse direction. It is observed that the crack density, the crack length, and the crack opening are much larger when the impact velocity is higher. From higher magnification SEM images, the microcracks are observed to nucleate from the interfaces between the $\gamma$-austenite and the $\mathrm{B} 2$ phase and propagate along the interfaces or cut through the $\mathrm{B} 2$ phase. This suggests that the interfaces between the $\gamma$-austenite and the B2 phase are the weakest sites, and the B2 phase is weaker than the $\gamma$ austenite under high strain rate tensile loading.

\section{Effect of the microstructure on the shock and spall behaviors of the HSSS}

The measured free surface velocity history profiles for experiments on the two microstructures conducted at similar impact velocities of $\sim 550 \mathrm{~m} / \mathrm{s}$ are shown in Fig. 10(a). Twowave structures are observed for all microstructures at these impact velocities, indicating the elastic-plastic shock response. Based on Eqs. (1) and (2), the stress at the HEL for the two structures can be obtained from the free surface velocity profiles in Fig. 10(a), and then the stress at HEL as a function of yield strength under quasi-static uniaxial stress conditions for the two microstructures is plotted in Fig. 10(b), along with the prediction from Eq. (6) as a dashed line. The stress at the HEL for the two microstructures are found to be much higher than the prediction from Eq. (6), indicating strong positive strain rate sensitivities for all microstructures. It should be noted that the impact conditions are similar for these two experiments (with a similar impact stress of $\sim 10 \mathrm{GPa}$ and a similar tensile strain rate of

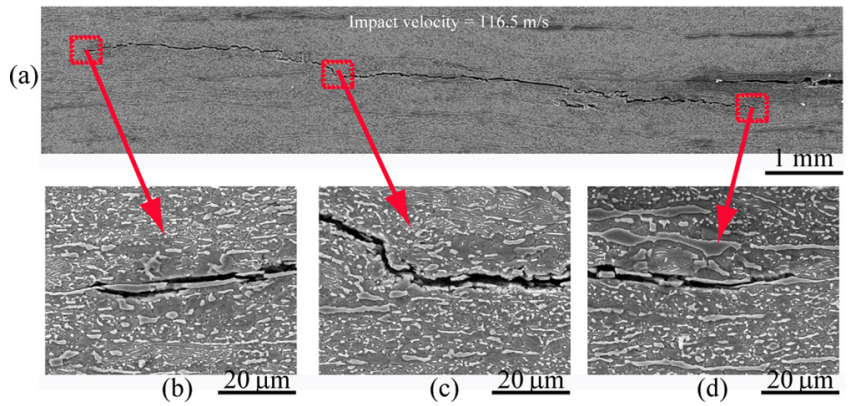

FIG. 9. The detailed SEM images of the cross-sectional surface parallel to the impact direction, showing the microcrack nucleation and propagation mechanisms in the HSSS.
$3-4 \times 10^{4} / \mathrm{s}$ ); thus, the spall strengths of these two experiments can be used to investigate the effect of the microstructure on the spall strength.

Ductile dynamic tensile failure (spall) of metals or alloys has been well known to be governed by the three stage microscopic processes, such as void nucleation, void growth, and final fracture through void coalescence. ${ }^{4-46}$ Void nucleation has been regarded as a cavitation instability in earlier research. ${ }^{47-49}$ It has now been widely accepted that the void nucleation is closely associated with second-phase particles in metals and alloys with two or multiple phases, and hard participates or inclusions might either debond from the ductile metal matrix or fracture internally during the dynamic tensile fracture process. ${ }^{50,51}$

Subsequent void growth has also been extensively investigated over the past several decades, and substantial micromechanical models have been proposed for understanding the quasi-static void growth ${ }^{44,52,53}$ or the dynamic void growth under extreme loading conditions. ${ }^{39,54-62}$ Moreover, a few modeling papers have suggested that the porosity achieved at the peak tensile stress is typically low $(<1 \%)$, and the void coalescence is achieved long after the peak tensile stress. ${ }^{63-65}$ Thus, it was proposed that the void coalescence behavior has no perceivable influence on the pull-back velocity and spall strength. ${ }^{63-65}$

In the previous research, the influences for the strain hardening ability and the yield strength under quasi-static uniaxial stress conditions on the spall strength have been experimentally and numerically investigated. ${ }^{63,65-67}$ Thus, the strain hardening ability and the yield strength under quasi-static uniaxial stress conditions, the HEL, and the spall strength have been plotted in Fig. 11 for the two microstructures. It is shown that the spall strength is higher when the strain hardening ability is higher for this HSSS. In a previous research for an $\mathrm{Al}-3 \mathrm{Mg}$ alloy, ${ }^{68}$ the spall strength increases with the increasing grain size when the grain size is below $25 \mu \mathrm{m}$. Their observations along with our results indicate that the spall strength is a microstructure dependent parameter of metals under impact tensile conditions. Similar to the observation in the recent work, ${ }^{67}$ our data also suggest that there is a tradeoff between the quasi-static yield strength/ HEL and the spall strength; thus, further work needs be done to focus on optimizing the combination of both mechanical properties for impact-resistant applications by tailoring the microstructure.

The SEM images on the spall fracture surfaces for the two microstructures impacted at similar velocities $(\sim 550 \mathrm{~m} / \mathrm{s})$ are displayed in Fig. 12. The spall fracture surfaces consist mostly of areas of ductile dimples for all microstructures. The larger dimples $(3.48 \mu \mathrm{m}$ for annealed state 2 as compared to $1.81 \mu \mathrm{m}$ for annealed state 1) are observed in the samples 


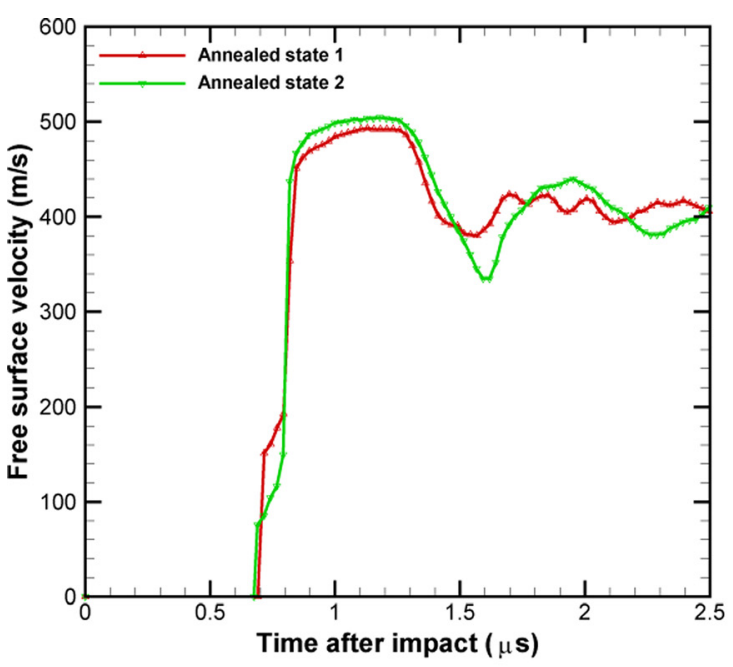

(a)

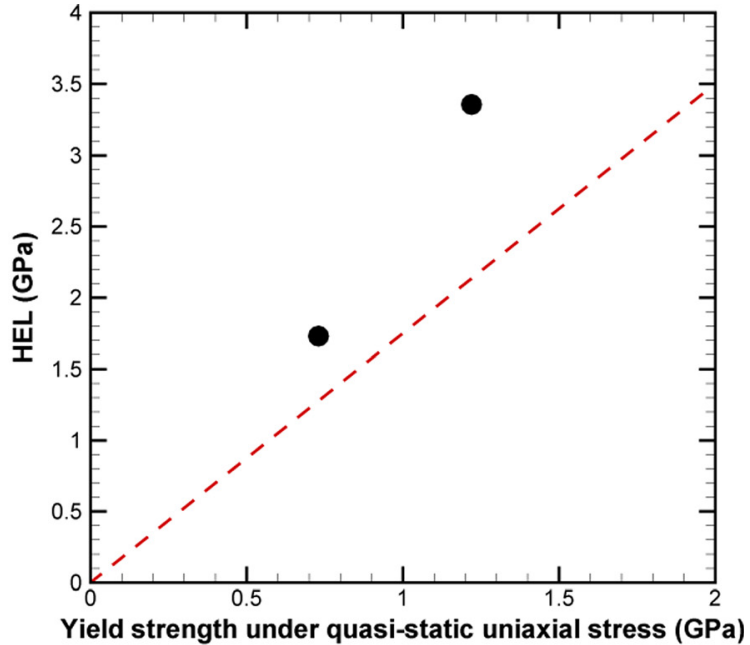

(b)

FIG. 10. (a) Free surface velocity history profiles for the plate-impact spall experiments conducted in the two microstructures at a similar impact velocity of $\sim 550 \mathrm{~m} / \mathrm{s}$. (b) The stress at HEL versus yield strength under quasi-static uniaxial stress conditions for the two microstructures. The dashed line in (b) represents the prediction from Eq. (6).

with annealed state 2, resulting in the higher spall strength, as shown in Fig. 11. These fracture surface observations are consistent with the microstructure features shown in Fig. 2, in which both granular and lamellar B2 phases are observed to have bigger size in annealed state 2 than those in annealed state 1. As indicated from Fig. 9, the microcracks are observed to nucleate from and propagate along the interfaces between the $\gamma$-austenite and the B2 phase, and thus, the interfaces are the weak points for the spall failure, and the fraction of interfaces could be considered as a controlling factor for the spall strength. Thus, based on the SEM images in Figs. 2(a) and 2(b), the lengths of the interface per unit area are calculated for the two microstructures. The fraction of interfaces is found to be much smaller for annealed state $2\left(0.71 \mu \mathrm{m}\right.$ per $\left.\mu \mathrm{m}^{2}\right)$ compared to that for annealed state $1\left(1.31 \mu \mathrm{m}\right.$ per $\left.\mu \mathrm{m}^{2}\right)$, resulting in higher spall strength for annealed state 2 . It is well known that the spall strength is highly dependent on the density of void nucleation sites, and thus, the higher density of the interface for this HSSS should result in lower spall

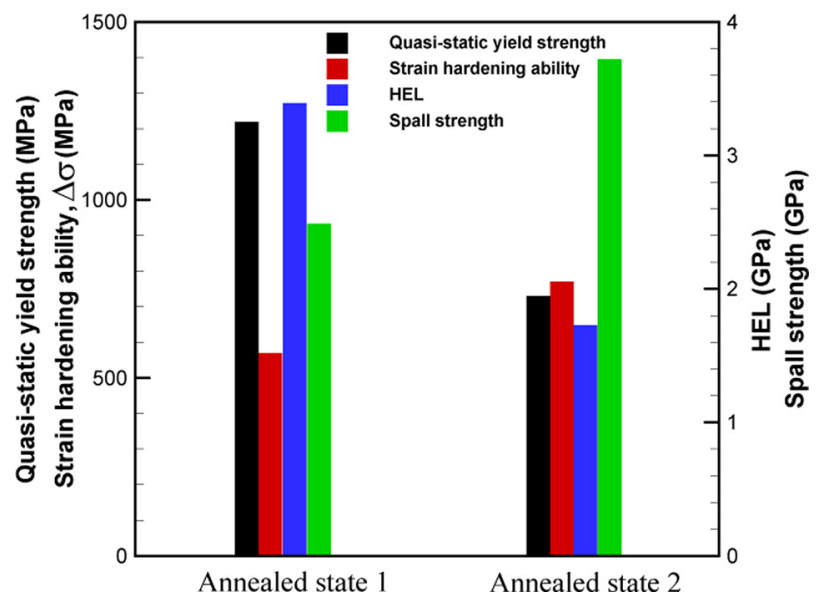

FIG. 11. The yield strength, the strain hardening ability under quasi-static uniaxial stress conditions, the HEL, and the resultant spall strength for the two microstructures. strength. This is very similar to the observation in the previous paper where the $\mathrm{Cu}$ single crystals with $\mathrm{SiO}_{2}$ particles exhibit lower spall strength due to an increase in interface density when compared to the $\mathrm{Cu}$ single crystals. ${ }^{69}$

Finally, the key results of all the experiments are summarized in Table II, including the shot \#, the microstructure, the impact stress, the tensile strain rate, the stress at HEL, and the spall strength. This HSSS is found to have high spall strengths $(2.92-3.72 \mathrm{GPa})$ when compared to other steels, such as Armco iron $(1.07 \mathrm{GPa}){ }^{31}$ 09G2S steel $(0.7-1.4 \mathrm{GPa}),{ }^{31}$ mild steel $(\sim 2.5 \mathrm{GPa}),{ }^{29}$ and $316 \mathrm{~L}$ stainless steel $(2.57-3.43 \mathrm{GPa}){ }^{32}$ It looks like that the tensile strain rates are higher for the experiments conducted at lower impact stress (below HEL) than those for the experiments conducted at higher impact stress (above HEL). Thus, the
Annealed state 1

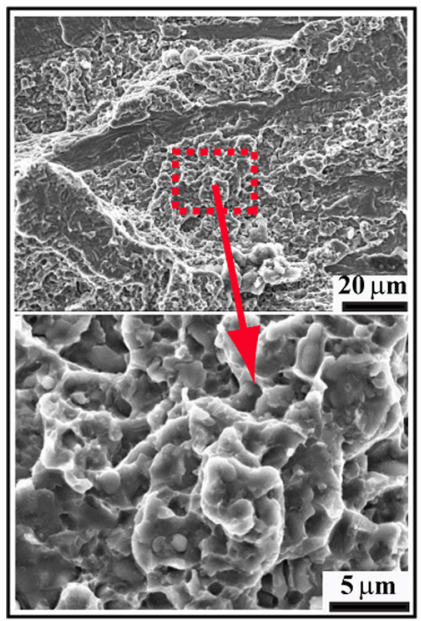

(a)
Annealed state 2

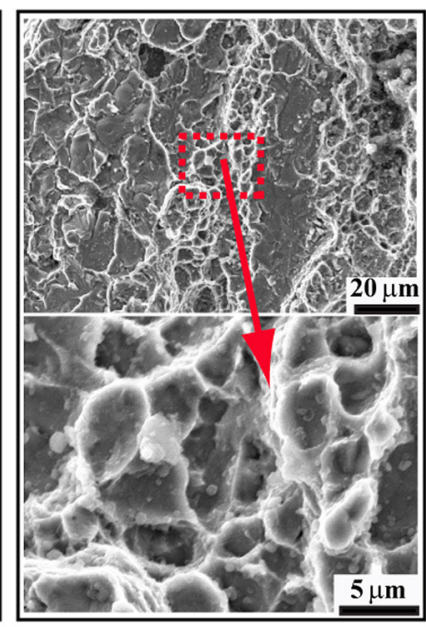

(b)
FIG. 12. SEM images of spall fracture surfaces for the samples with various microstructures at a similar impact velocity of $\sim 550 \mathrm{~m} / \mathrm{s}$ : (a) annealed state 1 and (b) annealed state 2 . 
TABLE II. The key results for all plate impact spall experiments.

\begin{tabular}{llcccc}
\hline \hline Shot \# & Microstructure & $\begin{array}{c}\text { Impact } \\
\text { stress } \\
(\mathrm{GPa})\end{array}$ & $\begin{array}{c}\text { Stress } \\
\text { at HEL } \\
(\mathrm{GPa})\end{array}$ & $\begin{array}{c}\text { Spall } \\
\text { strength } \\
(\mathrm{GPa})\end{array}$ & $\begin{array}{c}\text { Tensile } \\
\text { strain rate } \\
\left(10^{4} / \mathrm{s}\right)\end{array}$ \\
\hline 01A1 & Annealed state 1 & 2.46 & $/$ & $/$ & $/$ \\
02A1 & Annealed state 1 & 3.52 & 2.88 & 2.92 & 14.6 \\
03A1 & Annealed state 1 & 4.54 & 3.04 & 2.70 & 13.0 \\
04A1 & Annealed state 1 & 6.06 & 3.25 & 2.40 & 3.2 \\
05A1 & Annealed state 1 & 10.02 & 3.39 & 2.49 & 3.1 \\
01A2 & Annealed state 2 & 10.07 & 1.73 & 3.72 & 4.0 \\
\hline \hline
\end{tabular}

observed spall strength could also be related to the calculated tensile strain rate.

\section{CONCLUSIONS}

Shock and spall behaviors of the HSSS were studied through a series of plate-impact experiments. In the present study, the impact velocities were varied to investigate the effects of shock compression stress on the spall behaviors of the HSSS by keeping the same thickness of the flyer. The influences of the microstructure on the spall behaviors of the HSSS were also investigated by keeping the similar impact stress and the similar tensile strain rate. Two microstructures (annealed state 1 and annealed state 2) with different yield strengths, strain hardening abilities, and uniform elongations under quasi-static uniaxial tensile conditions were considered. The main findings are summarized as follows:

(1) With increasing impact stress up to about $6 \mathrm{GPa}$, the spall strength was found to decrease significantly and then level off with further increasing impact stress. This trend has been proposed to be attributed to the accumulation damage as the initial shock-induced compression wave propagates through the HSSS. The interfaces between $\gamma$-austenite and B2 phase were found to be the weakest sites during the dynamic tensile fracture process, and the microcracks were observed to nucleate at the interfaces and propagate along the interfaces or cut through the B2 phase.

(2) The HEL and the spall strength were found to be highly dependent on the microstructure. The higher the density of the void nucleation sites, the lower will be the spall strength. These results indicate that the spall strength should be a microstructure parameter of the HSSS under dynamic tensile conditions depending on the density of interfaces between $\gamma$-austenite and B2 phase. A tradeoff between the quasi-static yield strength/HEL and the spall strength was found for this HSSS; thus further work needs be done to obtain an optimizing combination of both mechanical properties for impact-resistant applications by tailoring the microstructure. These findings should be helpful for achieving better mechanical properties under shock loadings for the HSSS.

\section{ACKNOWLEDGMENTS}

This work was supported by NSFC [Grant Nos. 11672313, 11472286, and 11572328], the National Key
Basic Research Program of China [Grant Nos. 2012CB932203 and 2012CB937500], and the Strategic Priority Research Program of the Chinese Academy of Sciences [Grant No. XDB22040503].

${ }^{1}$ O. Bouaziz, S. Allain, and C. Scott, Scr. Mater. 58, 484 (2008).

${ }^{2}$ O. Grässel, L. Krüger, G. Frommeyer, and L. W. Meyer, Int. J. Plast. 16, 1391 (2000).

${ }^{3}$ S. Prüger, A. Seupel, and M. Kuna, Int. J. Plast. 55, 182 (2014).

${ }^{4}$ M. Calcagnotto, Y. Adachi, D. Ponge, and D. Raabe, Acta Mater. 59, 658 (2011).

${ }^{5}$ H. K. D. H. Bhadeshia, Sci. Tech. Adv. Mater. 14, 014202 (2013).

${ }^{6}$ G. Frommeyer and U. Bruex, Steel Res. Int. 77, 627 (2006).

${ }^{7}$ J. D. Yoo, S. W. Hwang, and K. T. Park, Mater. Sci. Eng. A 508, 234 (2009).

${ }^{8}$ S. W. Hwang, J. H. Ji, E. G. Lee, and K. T. Park, Mater. Sci. Eng. A 528, 5196 (2011).

${ }^{9}$ I. Gutierrez-Urrutia and D. Raabe, Scr. Mater. 68, 343 (2013).

${ }^{10}$ D. Raabe, H. Springer, I. Gutierrez-Urrutia, F. Roters, M. Bausch, J.-B. Seol, M. Koyama, P.-P. Choi, and K. Tsuzaki, JOM 66, 1845 (2014).

${ }^{11}$ R. Rana, C. Lahaye, and R. K. Ray, JOM 66, 1734 (2014).

${ }^{12}$ S. S. Sohn, H. Song, B. C. Suh, J. H. Kwak, B. J. Lee, N. J. Kim, and S. Lee, Acta Mater. 96, 301 (2015).

${ }^{13}$ S. H. Kim, H. Kim, and N. J. Kim, Nature 518, 77 (2015).

${ }^{14}$ J. G. Sevillano, Scr. Mater. 60, 336 (2009).

${ }^{15}$ S. Cheng, X. L. Wang, Z. L. Feng, B. Clausen, H. Choo, and P. K. Liaw, Metall. Mater. Trans. A 39A, 3105 (2008).

${ }^{16}$ S. Harjo, Y. Tomota, D. Neov, P. Lukas, M. Vrana, and P. Mikula, ISIJ Int. 42, 551 (2002).

${ }^{17}$ C. W. Sinclair, G. Saada, and J. D. Embury, Philos. Mag. 86, 4081 (2006).

${ }^{18}$ M. X. Yang, F. P. Yuan, Q. G. Xie, Y. D. Wang, E. Ma, and X. L. Wu, Acta Mater. 109, 213 (2016).

${ }^{19}$ F. P. Yuan, L. R. Tsai, V. Prakash, A. M. Rajendran, and D. P. Dandekar, Int. J. Solids Struct. 44, 7731 (2007).

${ }^{20}$ F. P. Yuan, V. Prakash, and J. J. Lewandowski, J. Mater. Res. 22, 402 (2007).

${ }^{21}$ P. Kumar and R. J. Clifton, J. Appl. Phys. 48, 4850 (1977).

${ }^{22}$ D. E. Grady and M. E. Kipp, High-Pressure Shock Compression of Solids (Springer-Verlag, 1993), p. 265.

${ }^{23}$ B. Glam, S. Eliezer, D. Moreno, L. Perelmutter, M. Sudai, and D. Eliezer, Int. J. Fract. 163, 217 (2010).

${ }^{24}$ X. Chen, J. R. Asay, S. K. Dwivedi, and D. P. Field, J. Appl. Phys. 99, 023528 (2006).

${ }^{25}$ C. L. Williams, C. Q. Chen, K. T. Ramesh, and D. P. Dandekar, J. Appl. Phys. 114, 093502 (2013).

${ }^{26}$ S. V. Razorenov, E. B. Zaretsky, and A. S. Savinykh, J. Phys.: Conf. Ser. 500, 112053 (2014).

${ }^{27}$ G. T. Gray III, N. K. Bourne, V. Livescu, C. P. Trujillo, S. MacDonald, and P. Withers, J. Phys.: Conf. Ser. 500, 112031 (2014).

${ }^{28}$ P. J. Hazell, G. J. Appleby-Thomas, E. Wielewski, C. Stennett, and C. Siviour, Acta Mater. 60, 6042 (2012).

${ }^{29}$ G. Y. Wang, Strain 47, 398 (2011).

${ }^{30}$ Z. W. Gu, X. G. Jin, and G. Q. Gao, J. Mater. Sci. 35, 2347 (2000).

${ }^{31}$ V. A. Ogorodnikov, E. Yu. Borovkova, and S. V. Erunov, Combust. Explos. Shock Waves 40, 597 (2004).

${ }^{32}$ G. T. Gray III, V. Livescu, P. A. Rigg, C. P. Trujillo, C. M. Cady, S. R. Chen, J. S. Carpenter, T. J. Lienert, and S. Fensin, EPJ Web Conf. 94, 02006 (2015).

${ }^{33}$ R. I. Hammond and W. G. Proud, Proc. R. Soc. London, Ser. A 460, 2959 (2004).

${ }^{34}$ A. S. Savinykh, G. V. Garkushin, S. V. Razorenov, S. Wolf, and L. Kruger, Combust. Explos. Shock Waves 51, 124 (2015).

${ }^{35}$ C. E. Morris, Los Alamos Shock Wave Profile Data (University of California Press, Berkeley, 1982).

${ }^{36}$ J. M. Brown, J. N. Fritz, and R. S. Hixson, J. Appl. Phys. 88, 5496 (2000).

${ }^{37}$ Z. J. Jiang, J. Y. He, H. Y. Wang, H. S. Zhang, Z. P. Lu, and L. H. Dai, Mater. Res. Lett. 4, 226 (2016).

${ }^{38}$ G. R. Fowles, J. Appl. Phys. 32, 1475 (1961).

${ }^{39}$ D. Chen, H. Tan, Y. Yu, H. Wang, S. Xie, G. Liu, and Z. Yin, Int. J. Impact Eng. 32, 1752 (2006).

${ }^{40}$ H. Schuler, C. Mayrhofer, and K. Thoma, Int. J. Impact Eng. 32, 1635 (2006). 
${ }^{41}$ R. L. Whelchel, D. S. Mehoke, K. A. Iyer, T. H. Sanders, and N. N. Thadhani, J. Appl. Phys. 119, 115901 (2016).

${ }^{42}$ C. Li, B. Li, J. Y. Huang, H. H. Ma, M. H. Zhu, J. Zhu, and S. N. Luo, Mater. Sci. Eng. A 660, 139 (2016).

${ }^{43}$ G. Seisson, G. Prudhomme, P.-A. Frugier, D. Hébert, E. Lescoute, A. Sollier, L. Videau, P. Mercier, M. Boustie, and L. Berthe, Int. J. Impact Eng. 91, 68 (2016).

${ }^{44}$ J. R. Rice and D. M. Tracey, J. Mech. Phys. Solids 17, 201 (1969).

${ }^{45}$ V. Tvergaard, Adv. Appl. Mech. 27, 83 (1989).

${ }^{46}$ C. Czarnota, S. Mercier, and A. Molinari, Int. J. Fract. 141, 177 (2006).

${ }^{47}$ R. Hill, The Mathematical Theory of Plasticity (Oxford University Press, Oxford, 1950), Vol. 11.

${ }^{48}$ Y. Huang, J. W. Hutchinson, and V. Tvergaard, J. Mech. Phys. Solids 39, 223 (1991).

${ }^{49} \mathrm{X}$. Wu, "The dynamic growth of voids in viscoplastic materials," Ph.D. thesis (The Johns Hopkins University, Baltimore, 2002).

${ }^{50}$ A. S. Argon, J. Im, and R. Safoglu, Metall. Trans. A 6, 825 (1975).

${ }^{51}$ A. Needleman, J. Appl. Mech. 54, 525 (1987).

${ }^{52}$ S. Nemat-Nasser and M. Hori, J. Appl. Phys. 62, 2746 (1987).

${ }^{53}$ M. Haghi and L. Anand, Int. J. Plast. 7, 123 (1991).

${ }^{54}$ S. T. S. Al-Hassani, D. Chen, and M. Sarumi, Int. J. Impact Eng. 19, 493 (1997).
${ }^{55}$ I. Z. Cooper and M. B. Rubin, Int. J. Impact Eng. 65, 174 (2014).

${ }^{56} \mathrm{~J}$. Li and H. Hao, Int. J. Impact Eng. 68, 41 (2014).

${ }^{57}$ J. N. Johnson, J. Appl. Phys. 52, 2812 (1981).

${ }^{58}$ Z.-P. Wang, J. Appl. Phys. 76, 1535 (1994).

${ }^{59} \mathrm{~W}$. Tong and G. Ravichandran, J. Appl. Mech. 62, 633 (1995).

${ }^{60}$ J. P. Feng, F. Q. Jing, and G. R. Zhang, J. Appl. Phys. 81, 2575 (1997).

${ }^{61}$ X. Y. Wu, K. T. Ramesh, and T. W. Wright, J. Mech. Phys. Solids 51, 1 (2003).

${ }^{62}$ J. W. Wilkerson and K. T. Ramesh, J. Mech. Phys. Solids 70, 262 (2014).

${ }^{63}$ C. Czarnota, N. Jacques, S. Mercier, and A. Molinari, J. Mech. Phys. Solids 56, 1624 (2008).

${ }^{64}$ T. W. Wright and K. T. Ramesh, J. Mech. Phys. Solids 56, 336 (2008).

${ }^{65}$ T. W. Wright and K. T. Ramesh, Int. J. Impact Eng. 36, 1242 (2009).

${ }^{66} \mathrm{R}$. Becker, "Direct numerical simulation of ductile spall failure," Int. J. Fract. (published online).

${ }^{67}$ J. W. Wilkerson and K. T. Ramesh, Phys. Rev. Lett. 117, 215503 (2016).

${ }^{68}$ N. A. Pedrazas, D. L. Worthington, D. A. Dalton, P. A. Sherek, S. P. Steuck, H. J. Quevedo, A. C. Bernstein, E. M. Taleff, and T. Ditmire, Mater. Sci. Eng. A 536, 117 (2012).

${ }^{69}$ R. W. Minich, J. U. Cazamias, M. Kumar, and A. J. Schwartz, Metall. Mater. Trans. A 35A, 2663 (2004). 